\title{
Release of PCBs from Silvretta glacier (Switzerland) investigated in lake sediments and meltwater
}

\author{
P. A. Pavlova ${ }^{1,2,3}$ - M. Zennegg ${ }^{1}$ - F. S. Anselmetti ${ }^{3,4}$ • P. Schmid ${ }^{1}$ - C. Bogdal ${ }^{6,7}$. \\ C. Steinlin ${ }^{6} \cdot$ M. Jäggi ${ }^{2}$ M. Schwikowski ${ }^{2,3,5}$
}

Received: 4 August 2015 / Accepted: 20 November 2015 / Published online: 7 December 2015

(C) Springer-Verlag Berlin Heidelberg 2015

\begin{abstract}
This study is part of our investigations about the release of persistent organic pollutants from melting Alpine glaciers and the relevance of the glaciers as secondary sources of legacy pollutants. Here, we studied the melt-related release of polychlorinated biphenyls (PCBs) in proglacial lakes and glacier streams of the catchment of the Silvretta glacier, located in the Swiss Alps. To explore a spatial and temporal distribution of chemicals in glacier melt, we combined two approaches: (1) analysing a sediment record as an archive of past remobilization and (2) passive water sampling to capture the current release of PCBs during melt period. In addition, we determined PCBs in a non-glacier-fed stream as a reference for the background pollutant level in the area. The PCBs in the sediment core from the Silvretta lake generally complied with trends of PCB emissions into the environment. Elevated
\end{abstract}

Responsible editor: Ester Heath

C. Bogdal

christian.bogdal@chem.ethz.ch

1 Empa, Swiss Federal Laboratories for Materials Science and Technology, Überlandstrasse 129, CH-8600 Dübendorf, Switzerland

2 PSI, Paul Scherrer Institute, CH-5232 Villigen, PSI, Switzerland

3 Oeschger Centre for Climate Change Research, University of Berne, CH-3012 Bern, Switzerland

4 Institute of Geological Sciences, University of Berne, CH-3012 Bern, Switzerland

5 Department of Chemistry and Biochemistry, University of Berne, CH-3012 Bern, Switzerland

6 Institute for Chemical and Bioengineering, ETH Zurich, Vladimir-Prelog-Weg 1, CH-8093 Zürich, Switzerland

7 Agroscope, Institute for Sustainability Sciences ISS, CH-8046 Zürich, Switzerland concentrations during the most recent ten years, comparable in level with times of the highest atmospheric input, were attributed to accelerated melting of the glacier. This interpretation is supported by the detected PCB fractionation pattern towards heavier, less volatile congeners, and by increased activity concentrations of the radioactive tracer ${ }^{137} \mathrm{Cs}$ in this part of the sediment core. In contrast, PCB concentrations were not elevated in the stream water, since no significant difference between pollutant concentrations in the glacier-fed and the non-glacier-fed streams was detected. In stream water, no current decrease of the PCBs with distance from the glacier was observed. Thus, according to our data, an influence of PCBs release due to accelerated glacier melt was only detected in the proglacial lake, but not in the other compartments of the Silvretta catchment.

Keywords Sediments $\cdot$ Polychlrinated biphenyls $\cdot$ Persistent organic pollutants · Meltwater · Glaciers · Passive sampling

\section{Introduction}

Polychlorinated biphenyls (PCBs) represent a group of anthropogenic compounds, used as plasticizers, insulating and cooling liquids, which have been released into the environment since the mid-twentieth century. Because of their persistence, toxicity, bioaccumulation and long-range atmospheric transport, production and use of PCBs were banned with the United Nations Stockholm Convention on Persistent Organic Pollutants in 2004 (UNEP 2004). The physical-chemical properties of considerable volatility and low water solubility, together with their poor degradability, drive the widespread distribution of PCBs in the environment. Although PCBs are no longer produced, they are still ubiquitous, also in remote areas, far away from their initial sources. Because of the 
specific meteorology of high-elevation areas including low temperatures, high wind speeds, and high precipitation rates, PCBs can accumulate at high altitudes, despite of their remoteness (Wania and Westgate 2008). In alpine environments, glaciers represent archives of past climate and atmospheric composition and store persistent chemicals, such as PCBs, in the ice. As a result of melting, the stored PCBs are released and consequently, glaciers represent secondary sources for these legacy pollutants (Bizzotto et al. 2009; Bogdal et al. 2009; Schmid et al. 2011).

Once released to water bodies, PCBs are preferably bound to suspended particles because of their high sorption affinity. Hence, sediments represent a useful tool for monitoring PCBs in water bodies and may provide historical records of pollution (Bogdal et al. 2008; Thevenon et al. 2013). Rate, area and regime of sedimentation strongly depend on particle composition, amount and size, and variability in water runoff. These parameters can complicate the interpretation of pollutant records in sediments, especially in high mountain areas, where hydrological regimes are highly variable, and available data on these regimes are often scarce. In addition, PCBs in water occur also partly in the dissolved phase, which is eventually transported with the water flow and is not deposited with the settling particles. Thus, to capture the fraction of PCBs in the mobile water phase, PCBs have been monitored in glacier streams with different spatial and temporal resolutions (Bizzotto et al. 2009; Nellier et al. 2015; Vilanova et al. 2001). However, single water samples represent a snapshot of the pollutant concentration, which can be highly variable depending on the sampling period and location, diurnal cycle of glacier melt, or meteorological conditions. Moreover, the accurate determination of PCBs in small water samples is highly challenging, due to the very low concentrations and, thus, susceptibility to sample contamination and analyte losses. As an alternative to single grab samples, passive water sampling has been successfully applied for monitoring trace contaminants in flowing water bodies (Moschet et al. 2014). For hydrophobic compounds, such as PCBs, polydimethylsiloxane (PDMS) passive samplers proved to be a suitable sampling approach. Since being exposed in water for a longer period (usually about 4 weeks), the measured pollutant load represents an integral over the whole sampling period. Finally, the analysis of PCBs enriched in PDMS samples is more straightforward than in single water samples and, therefore, complements bulk water sampling.

Bizzotto et al. (2009) compared concentrations of PCBs in glacial streams obtained at varying distances from the glacier terminus with concentrations in a non-glacial stream located in the vicinity. In the glacial stream, no differences in the loads with the distance from the glacier terminus were observed, and the PCB contamination in the studied area was ascribed to annual snow melt. Bettinetti et al. (2008) attributed the concentrations of PCBs in mussels in the glacier-fed lake Iseo,
Italy, to the significant release of PCBs by glacier melting in the warm summer 2003. Bogdal et al. (2009) and Schmid et al. (2011) demonstrated increasing concentrations of PCBs and other persistent chemicals in the recent sediment layers in glacier-fed lakes in the Alps. However, no direct measurements of PCBs in the outflow of glacier-fed lakes are available. Also, a cross-validation between loads of PCBs in sediment and associated water concentrations has not been performed so far.

Here, we provide PCB data from a sediment record covering the period 1950-2010 from the proglacial lake, located just below the terminus of the Silvretta glacier in the Swiss Alps. We complement the sediment analysis with passive water sampling of PCBs at two different locations downstream the glacial lake during the months of September and October in the two consecutive years 2012 and 2013. We also analysed samples from a non-glacier-fed stream assumed to be representative for the background PCB level in the same area. In the following, we study concentrations and pollutant patterns in the different matrices and locations, with the goal to improve the understanding of the release and redistribution of PCBs from melting glaciers.

\section{Methods}

\section{Lake sediments — drilling, sampling and dating}

Silvretta glacier in the Swiss Alps and the corresponding two proglacial lakes were chosen as a study site. In the upper Silvretta lake (S1), passive samplers were deployed to assess the current PCB loads. Visual inspection of this lake throughout the melt season revealed particle-poor water indicating that it no longer receives meltwater from the glacier. To study the historical trends of PCBs in glacier runoff, we therefore analysed a sediment core from the lower Silvretta lake (S2), located just below the Silvretta glacier terminus (Fig. 1). This lake was formed around 1950 due to the retreat of the glacier. The lacustrine sediments in this proglacial setting consist of clastic varves (Anselmetti et al. 2007; Leemann and Niessen 1994).

Two sediment coring campaigns were conducted. In August 2010, three sediment cores (each $\sim 1 \mathrm{~m}$ in length) were taken from an inflatable boat using a short gravity corer. In addition, surface cores (30 cm in length) were retrieved at the same locations with less weight to obtain undisturbed surface sediment. In order to extend the record, a longer core was collected in February 2012. This second coring campaign was conducted from the surface of the frozen lake after removing the overlaying snow and ice. A manual percussion piston corer (Uwitec) was used to recover a 2.5-m long sediment core that reached the underlying moraine and thus covers the time back to the formation of the lake around 1950 (Fig. 1).

The sediment cores were collected according to the standard protocol in PVC tubes with an inner diameter of $5.9 \mathrm{~cm}$. In the 


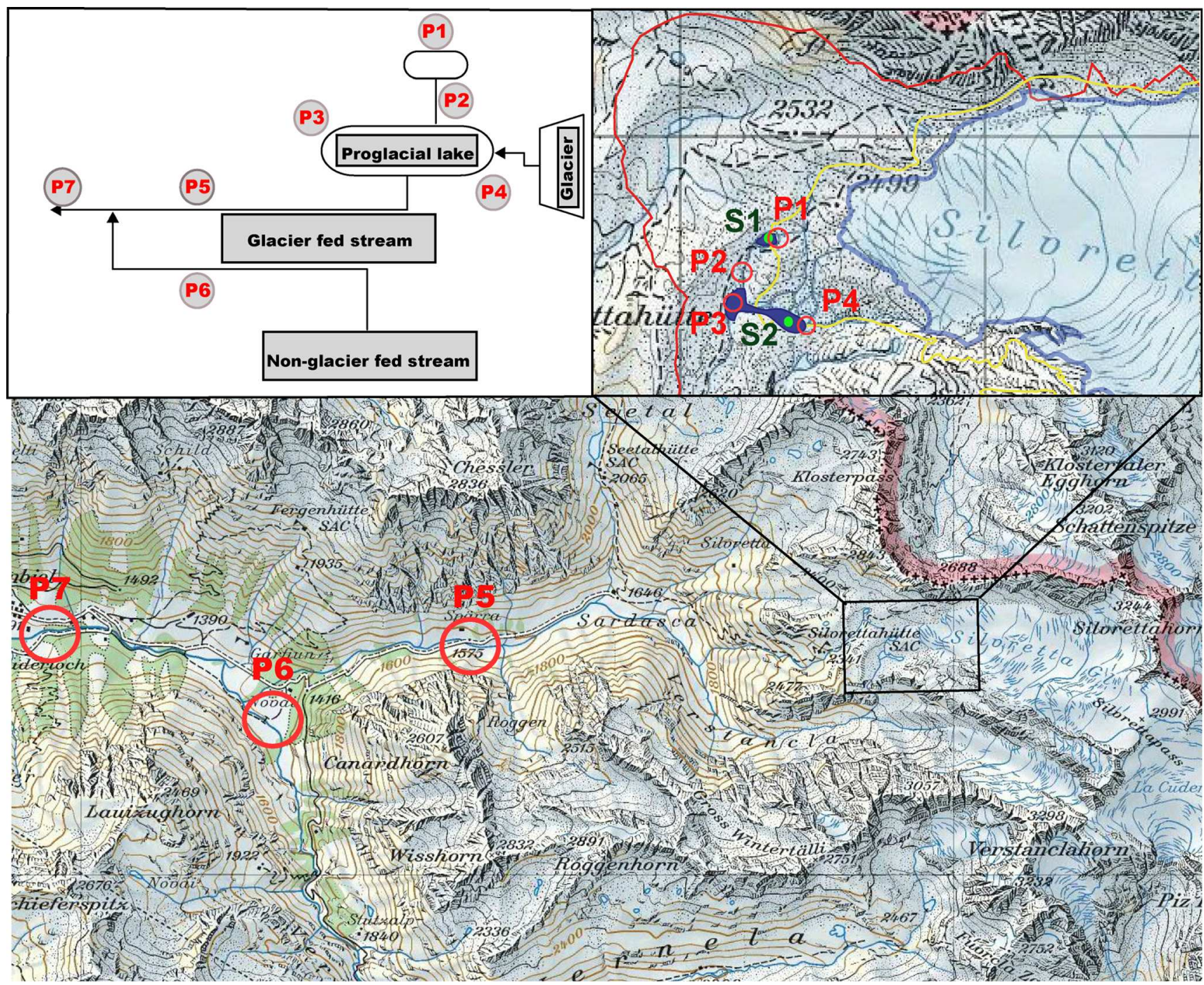

Fig. 1 Map of the Silvretta and Verstancla glaciers and their catchment area, showing the locations of sediment sampling (lake S2) and of the passive water samplers (P1-P7) (C) 2014 swisstopo JD100043). The two

laboratory, they were split lengthwise into two halves. After drying at room temperature and removing the surface layer, the varved structure of the cores was inspected. Based on shortcore to long-core correlation, a composite section, which contained the best preserved sediments, was defined. The sampling resolution of the core was $2 \mathrm{~cm}$ for the upper section (0$100 \mathrm{~cm})$ and $10 \mathrm{~cm}$ for the lower section $(110-210 \mathrm{~cm})$.

The age model of the composite core was compiled using radioactive isotopes of anthropogenic origin. Caesium-137 $\left({ }^{137} \mathrm{Cs}\right)$, which is known to have two distinct activity peaks in Western Europe (Appleby et al. 2001). corresponding to the peak fallout of nuclear bomb testing (1963) and the Chernobyl power plant accident (1986), was measured gamma-spectrometry (662 keV) on 10-g samples at Eawag Dübendorf using low background, high-purity Germanium (HPGe) well detectors (Canberra) (Elbert et al. 2011). An independent confirmation of the dating was provided by activity measurements of the lakes S1 and S2 are highlighted in dark blue. Coloured lines show the glacier's extent in 1849 (red), 1959 (yellow), and 2003 (grey); adapted from A. Bauder (Huss and Bauder 2009)

actinides plutonium-239 $\left({ }^{239} \mathrm{Pu}\right)$ and americium-241 $\left({ }^{241} \mathrm{Am}\right)$, which were emitted during the same events. However, after the Chernobyl accident, ${ }^{239} \mathrm{Pu}$ was deposited more locally and thus did not reach the Silvretta area. The actinides of selected sediment samples showing ${ }^{137} \mathrm{Cs}$ maxima were chemically separated and electrolysed and measured by alpha-spectrometry (Octête, EG\&G-Ortec) at the Paul Scherrer Institute.

\section{Passive water sampling}

In passive water samplers, the target analytes (here PCBs) sorb to the passive sampler phase (here case polydimethylsiloxane, PDMS) until equilibrium is reached between the concentrations in the passive material phase and the water, which is defined by the partition coefficient $\mathrm{K}$ :

$K=C_{P D M S} / C_{\text {water }}$ 
Uptake of PCBs by passive samplers depends not only on the kinetics but also on environmental parameters, here predominantly the flow velocity. The uptake rate increases with increasing flow velocity. In the case of glacier-fed streams, there is a strong variation in diurnal flow rate. Since there is no continuous flow data available, we assume an average comparable flow velocity between all flowing water bodies. This assumption implies that concentrations at sites with standing waters might be underestimated compared to sites with fast flowing waters. Additional parameters, such as the water temperature, may also influence the uptake. Since temperatures at the selected sites are similar, we do not correct for this parameter. Also, the formation of a biofilm on the passive samplers and the presence of dissolved organic carbon, which both reduce the sorption capacity of passive samplers, is negligible due to the very low bioactivity of nutrient-poor meltwater.

For the preparation of the samplers, PDMS foils (1-mm thick silicone membrane SSPM823) with white 1-mm thick virgin Teflon liner (J-Flex Rubber Products) were used. Pieces of $10 \times 40 \mathrm{~cm}$ were cut and weighted. The foil was washed and pre-extracted using Soxhlet with ethyl acetate for $96 \mathrm{~h}$ and with methanol for $48 \mathrm{~h}$. Until use, clean PDMS foils were kept in methanol in sealed glass bottles. Foils were taken out in the field and fixed with screws on concrete-based holders or on heavy stones in the case of lentic water (proglacial lakes). Exposure duration of the passive samplers was 4 weeks. Flow velocity and temperature were measured at deployment and harvest of the samplers at every site. After exposure, PDMS foils were cut off, washed from particle deposits and stored in precleaned glass bottles at $-20{ }^{\circ} \mathrm{C}$ until analysis.

We conducted PDMS sampling in two consecutive years, starting in August. In 2012, passive samplers were exposed for 4 weeks in the two proglacial lakes (sites P1, P3 and P4 in Fig. 1) and the runoff stream from lake S1 to S2 (P2). In order to evaluate the loads of pollutants further down the valley, we installed PDMS samplers in the Verstancla stream (P5 and P7), receiving the meltwater from the Silvretta glacier and the Verstancla glacier, located $0.5 \mathrm{~km}$ south of the Silvretta glacier. Since both glaciers are located at the approximately same elevation, we assume similar environmental conditions. However, the Verstancla glacier has a roughly three times smaller surface area and, therefore, is contributing less to the runoff in the river. Downstream in the catchment area, we conducted a series of PDMS sampling campaigns from August to October in 2012 and 2013, respectively. In 2012, we sampled the Verstancla stream (P5) for two 4-week periods. In 2013, the study was extended to three sampling sites over three 4-week periods: the glacier-fed Verstancla stream (P5), the non-glacier-fed Vereina stream (P6) and another location in the Verstancla stream after confluence with the Vereina stream (P7).
To estimate aqueous concentrations of $\mathrm{PCBs}$ in $\mathrm{pg} / \mathrm{L}$ based on the passive sampler data, the total mass in pg of the analytes sampled per PDMS was divided by a sampling rate in $\mathrm{L} / \mathrm{d}$ and multiplied by the exposure/sampling time in $\mathrm{d}$, as described by Moschet et al. (2014). For calculating sampling rates, we used elimination of performance reference compounds (PRCs), which had been spiked onto the PDMS prior to exposure. As PRCs we used ${ }^{13} \mathrm{C}_{12}$-labelled PCB 1, PCB 3, PCB 9, PCB 37, PCB 79, PCB 111 and PCB 162 with the same number of chlorine atoms in the molecules as the analytes, to ensure similar environmental behaviour. Detailed descriptions regarding the elimination method setup are given by Moschet et al. (2014). The calculated sampling rates were corrected according to experimentally derived flow-depended elimination coefficients according to the method described by Vermeirssen et al. (2012) and applied here to PDMS samplers. In addition, 2-L bulk water samples were collected in September and October close to the passive sampler locations P5 and P6 with pre-cleaned glass bottles. These are further used for validation of the sampling rates and aqueous concentrations of PCBs in the catchment area.

\section{PCB analysis}

We analysed the indicator PCB congeners $28,52,101,138$, 153 and 180 , denoted thereafter as iPCBs. Immediately before use, all the glassware was baked out and rinsed with acetone and dichloromethane. Freeze-dried, pulverised lake sediments (5 g per sample) were spiked with ${ }^{13} \mathrm{C}_{12}$-labelled PCB analogues as internal standards and Soxhlet-extracted with $n$-hexane/dichloromethane $(1: 1 v / v)$ for $12 \mathrm{~h}$. After pre-concentration, the extracts were cleaned over liquid chromatography columns packed with neutral silica gel and anhydrous sodium sulphate and eluted with $n$-hexane (Bogdal et al. 2009). PDMS samplers, spiked with ${ }^{13} \mathrm{C}_{12}$-labelled internal standards, were Soxhlet-extracted with methanol for $24 \mathrm{~h}$. The extracts were pre-concentrated and treated with concentrated sulphuric acid, followed by clean-up with silica gel chromatography (identically to the sediment samples). The cleaned sediment and passive sampler extracts were analysed by gas chromatography coupled to electron ionisation highresolution mass spectrometry (GC/EI-HRMS). Samples were injected in splitless mode (split valve closed for $20 \mathrm{~s}$ ) at an injector temperature of $260{ }^{\circ} \mathrm{C}$ with hydrogen at $50 \mathrm{kPa}$ as carrier gas. The mass spectrometer was tuned to a mass resolution of at least 8000 . Using single ion monitoring (SIM), the two most abundant signals of the molecular ion clusters of the analytes were recorded. Details regarding the measurement procedure and the quantification based on isotope-labelled internal standards are provided in Pavlova et al. (2014). The analytical procedure for the sediments samples included the preparation of blank samples, following the described clean- 
up procedure from extraction to GC injection parallel to the samples (one per series), with an average load of the sum of all iPCB congeners of $176 \pm 67 \mathrm{pg}(n=6)$. The average recovery of the internal standards was controlled by the addition of a recovery standard prior to analysis $\left({ }^{13} \mathrm{C}_{12}\right.$-labelled PCB 70) and exceeded $80 \%$.

Water samples $(2 \mathrm{~L})$ were extracted using highperformance polymeric solid phase extraction (SPE) on $500 \mathrm{mg}$ Strata-XL 100- $\mu \mathrm{m}$ polymeric reversed phase (Phenomenex). In order to avoid additional contamination, the water samples were not filtered. They were spiked with internal standards and were passed through a $6 \mathrm{~mL}$ SPE cartridge at a flow rate of $3-5 \mathrm{~mL} / \mathrm{min}$ using a peristaltic pump. The loaded cartridge was dried by the application of vacuum for $30 \mathrm{~s}$, and the PCBs were eluted with $6 \mathrm{~mL}$ of $n$-hexane. The volume was reduced to $30 \mu \mathrm{l}$ at room temperature under a gentle stream of nitrogen and after the addition of the recovery standard $\left({ }^{13} \mathrm{C}_{12}\right.$ labelled PCB 70$)$, the samples were directly measured by GC/EI-HRMS without further clean-up. The instrumental limit of detection (LOD) was in the range of 10-20 pg /L for the single PCBs (Pavlova et al. 2014). In addition, three SPE blanks with an average value of $33 \mathrm{pg} / \mathrm{L}$ were analysed. All data presented is not blank corrected. By the use of the internal standard quantification procedure, the data is implicitly corrected for recovery.

\section{Results}

\section{Age model for the Silvretta lake}

In the proglacial Silvretta lake, sediment varves are formed by seasonal variation of the particle size. In summer, coarse particles from the glacier are transported with melt or rain water to the lake, producing several graded layers per year (Anselmetti et al. 2007). In contrast, in winter, when the lake surface is frozen, no particles enter the lake, so that sedimentation is dominated by the remaining finest particles that slowly settle down in the quiet water column forming a well-defined layer. The Silvretta Lake is characterised by a rather complex hydrology so that in some cases, varves cannot be differentiated distinctively and, thus, they could not be used for dating. In addition, several prominent high-energy coarse sedimentary events occurred, representing major short-lived runoff pulses delivering large amounts of particles. They also show enhanced ${ }^{137} \mathrm{Cs}$ values, which were interpreted to originate from resuspension of formerly deposited sediment (Fig. 2). Consequently, they were excluded from the background age model and the PCB analysis. After removal of these sedimentary event layers, the age-depth relationship for the core was obtained through linear interpolation between the two identified ${ }^{137} \mathrm{Cs}$ horizons (1963, 1986) and the time of formation of the lake in 1950 . The

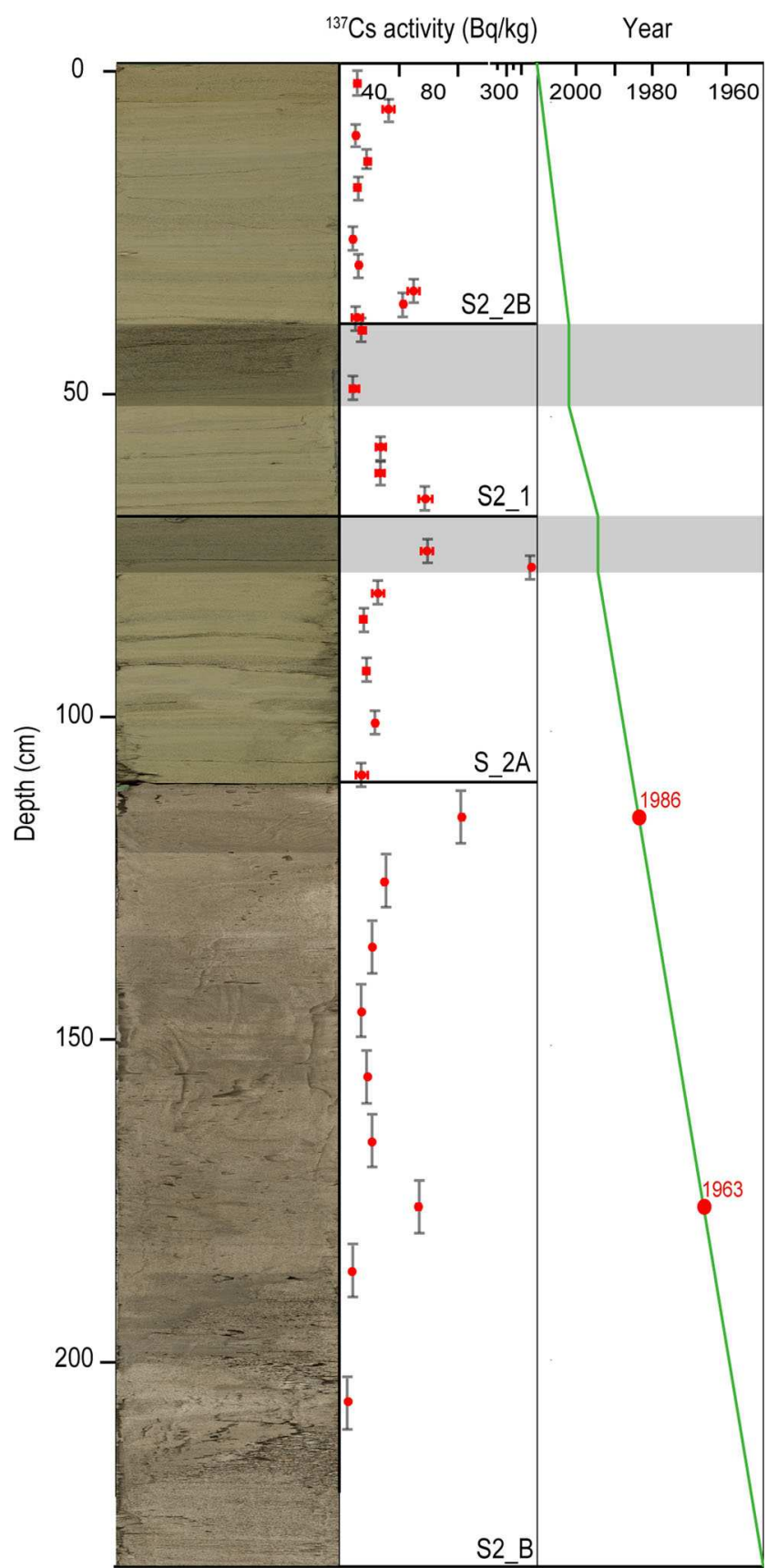

Fig. 2 Age-depth model of the Silvretta lake sediment (red dots \pm standard error represented by horizontal bars). The vertical grey bars represent the sample thickness. The grey-shaded area represents the coarse sediment layers that were excluded from the analysis

assignment of the ${ }^{137} \mathrm{Cs}$ horizons is supported by the ${ }^{239} \mathrm{Pu}$ and ${ }^{241} \mathrm{Am}$ activity concentrations, which increased with depth. In addition, all the measured sediment samples showed an isotope ratio $\left({ }^{241} \mathrm{Am} /{ }^{239,240} \mathrm{Pu}\right)$ of around 0.4 , which is characteristic for the bomb test signal and shows that there is no input from the Chernobyl accident in this section of the core (Röllin et al. 2013). Based on the age model (Fig. 2), the average annual sedimentation rate for the sediment core is $4.8 \mathrm{~cm} / \mathrm{yr}$. 


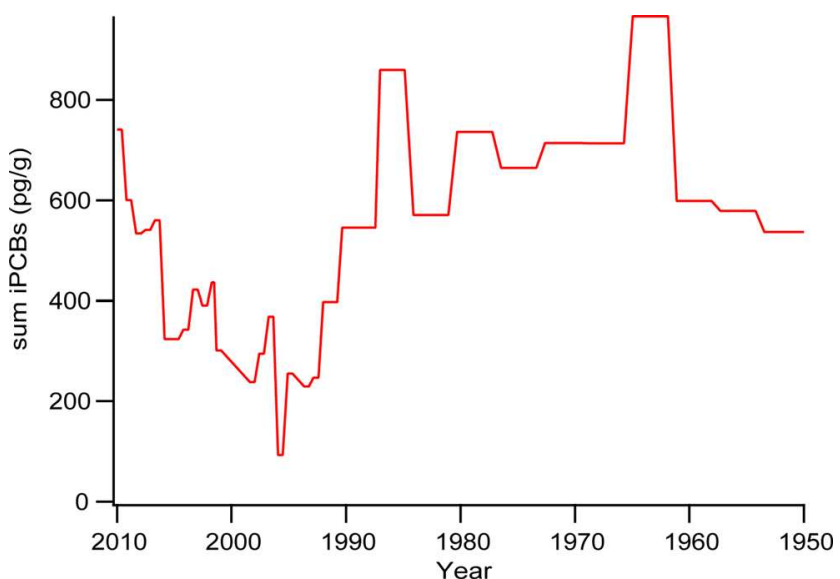

Fig. 3 Time trend of the concentration of the sum of iPCBs in the composite sediment core from S2

\section{iPCBs in the sediment core from the proglacial lake}

The sum of the iPCB concentrations in the sediment core from the proglacial lake varies between 100 and $800 \mathrm{pg} / \mathrm{g}$ (dry weight) (Fig. 3). The highest concentrations $(>800 \mathrm{pg} / \mathrm{g}$ ) are observed in the 1960 s to the 1980 s, followed by a rapid decrease to background levels. In the period 2000 to 2010, the concentrations of iPCBs gradually increased again to $700 \mathrm{pg} / \mathrm{g}$.

\section{iPCBs concentration in water from the proglacial lake and the streams}

At sampling location P1, we observed the lowest loads of all sampling sites; the iPCB concentration was below $100 \mathrm{pg} / \mathrm{g}$ PDMS (Table 1). Further down in the valley, the obtained values were very homogeneous. Slightly higher PCB loads were found in the Verstancla stream upstream of the inflow of the Vereina stream (P5) in September in two consecutive years. The congener pattern of the PCBs in all passive samplers and the surface sediment is dominated by PCB 101, 138 and 153 (Fig. 4).

In order to estimate the overall $\mathrm{PPCB}$ load in the Silvretta catchment area, we calculated $\mathrm{PCB}$ concentrations in water based on the PDMS data and compared them to concentrations in bulk water samples collected during deployment of the passive samplers. The calculation is based on the elimination of PRCs spiked on the samplers and reveals similar conditions in all locations. The sampling rate of the PDMS at the locations P5-P7 is between 12 and $14 \mathrm{~L} / \mathrm{d}$, with the lowest rates in the Vereina (P6) and the highest in the Verstancla stream (P5) before discharging into Vereina. These values are in accordance to previously published data of 10-25 L/d and 15-75 L/d (Moschet et al. 2014; Rusina et al. 2010). The obtained iPCB concentrations at the locations P5-P7 are quite uniformly below $20 \mathrm{pg} / \mathrm{L}$. The concentrations of iPCBs in the bulk water samples collected in September-October 2013 in the Verstancla and Vereina streams range between 50 and $100 \mathrm{pg} / \mathrm{L}$ with an average value of $66 \mathrm{pg} / \mathrm{L}$.

\section{Discussion}

\section{Release of radioactive isotopes from melting glaciers}

The accelerated melting of the Silvretta glacier ice results in the remobilisation of trace species contained in the ice. We compared the ${ }^{137} \mathrm{Cs}$ activity data with the $\mathrm{PCB}$ concentration in the sediment from the Silvretta lake (Fig. 5). In the atmosphere, these trace species are bound to particles and are deposited dry or with precipitation onto the surfaces (glacier, lake). During the years 1960 to 1980 (100 to $200 \mathrm{~cm}$ sediment depth), the glacier was still accumulating, and primary deposition processes determined the $\mathrm{iPCB}$ and ${ }^{137} \mathrm{Cs}$ sediment concentration profiles. There is no interference of released ${ }^{137} \mathrm{Cs}$ with the direct atmospheric input in 1963 and 1986; therefore, the ${ }^{137} \mathrm{Cs}$ maxima can still be used for dating of the sediment core. In contrast, in the recent period 1990 to 2010 ( 0 to 100 $\mathrm{cm}$ sediment depth), the glacier melting resulted in the outflow of meltwater and particles and, thus, also remobilisation of trace chemicals. Whereas for PCBs, previous studies have already provided evidence for the accelerated release from glaciers in the Swiss Alps (Bogdal et al. 2009; Schmid et al. 2011). we can show here that similar processes occur for

Table 1 Loads of iPCBs on the PDMS passive samplers and corresponding iPCB concentrations in water

\begin{tabular}{|c|c|c|c|c|c|c|c|c|c|c|c|c|}
\hline \multirow[b]{2}{*}{ Sampling site } & \multicolumn{4}{|c|}{ Proglacial lakes } & \multicolumn{4}{|c|}{ Glacier-fed stream } & \multicolumn{2}{|c|}{ Non-glacier-fed stream } & \multicolumn{2}{|c|}{ Mixed stream } \\
\hline & $\mathrm{P} 1$ & $\mathrm{P} 2$ & P3 & $\mathrm{P} 4$ & P5 & P5 & P5 & P5 & P6 & P6 & P7 & P7 \\
\hline Sampling period & Sep & & & & Sep. 12 & Oct. 12 & Sep. 13 & Oct. 13 & Sep. 13 & Okt. 13 & Sep. 13 & Okt. 13 \\
\hline Sum iPCBs pg/g PDMS & 78 & 142 & 158 & 465 & 250 & 109 & 280 & 226 & 143 & 180 & 201 & 177 \\
\hline Av. sampling rate in $\mathrm{L} / \mathrm{d}$ & & & & & 14 & 14 & 14 & 14 & 13 & 13 & 12 & 12 \\
\hline Av. PDMS mass in $g$ & & & & & 29 & 29 & 29 & 29 & 29 & 29 & 28 & 28 \\
\hline Av. calculated concentration $\mathrm{pg} / \mathrm{L}$ & & & & & 17 & 7 & 19 & 16 & 11 & 13 & 15 & 13 \\
\hline Bulk water samples $(\mathrm{pg} / \mathrm{L})$ & & & & & & & 73 & 52 & 51 & 55 & 100 & 100 \\
\hline
\end{tabular}


Fig. 4 iPCBs in the PDMS samplers in the Silvretta catchment area

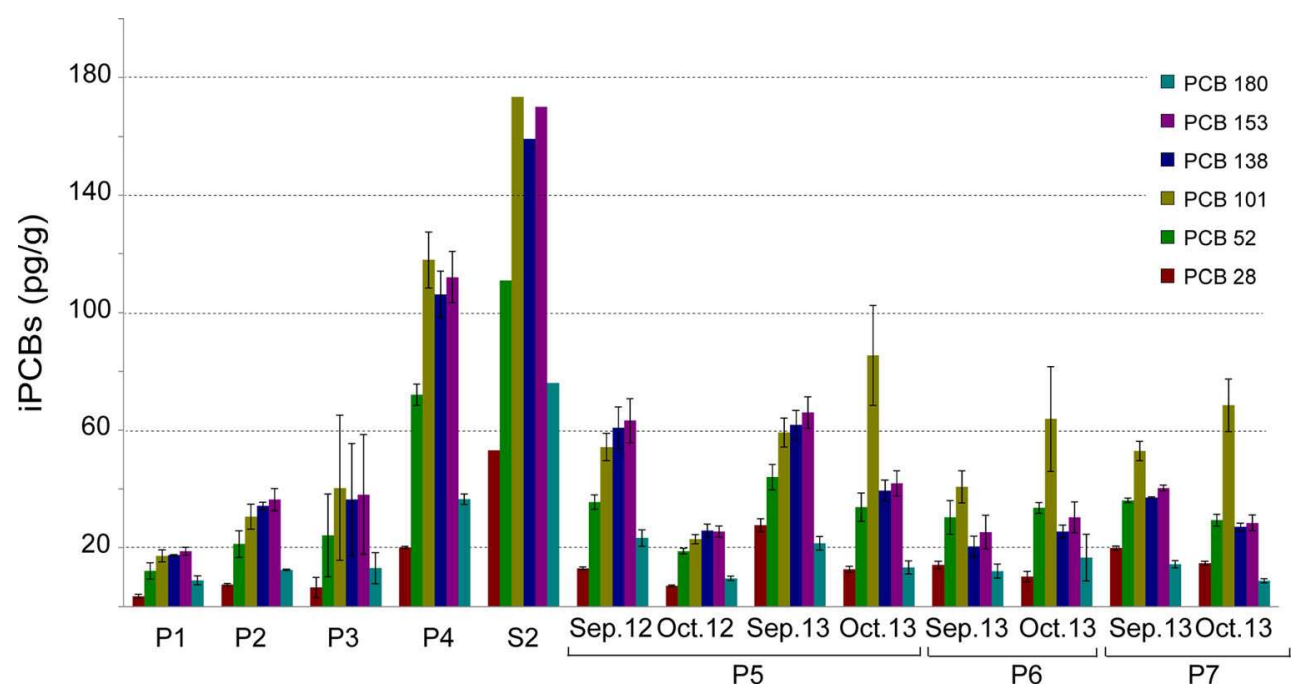

radioactive tracers, as indicated by the increased ${ }^{137} \mathrm{Cs}$ sediment concentrations at 40- and 70-cm depth.

\section{Historical trends of atmospheric input vs. secondary deposition of PCBs in lake sediments}

The loads of iPCBs in the sediment from Silvretta lake (sum iPCBs $100-800 \mathrm{pg} / \mathrm{g}$ dry weight) correspond to the values reported for other proglacial lakes in the Alps, i.e. Lake Stein (300-900 pg/g) (Schmid et al. 2011) and Lake Oberaar $(500-1000 \mathrm{pg} / \mathrm{g})$ (Bogdal et al. 2009). We observed the highest concentrations (>700 pg/g) during the period 19601980 , which are in good agreement with the studies mentioned above and the temporal emission trends of PCBs (Breivik et al. 2007). The consecutive decrease of concentrations after the late $1980 \mathrm{~s}$ to a background level of $20 \mathrm{pg} / \mathrm{g}$ is probably due to discontinuing PCB production and disposal restrictions at that time. Increasing concentrations in the sediments during the last 10 years are interpreted as secondary release from the melting ice, a phenomenon previously observed for other sites in the Alps and the Arctic (Bettinetti et al. 2011; Bizzotto et al. 2009; Blais et al. 2001; Bogdal et al. 2009). Further, depending on their physical-chemical properties (i.e. water solubility, hydrophobicity, vapour pressure, etc.), PCBs exhibit homolog-specific behaviour in glacier ice (Steinlin et al. 2014). which can result in fractionation along the pathway from primary emission sources to the meltwater. Sediments originating from the period influenced by glacier melt are enriched in heavier, highly chlorinated homologs such as PCB 138, 153 and PCB 180. This is in agreement with Steinlin et al. (2014). who showed that light, less chlorinated congeners (PCB 28 and PCB 52) are mainly re-emitted back to the atmosphere after deposition on the glacier, because of their high volatility (Fig. 6).

\section{Recent concentrations of PCBs in the Silvretta proglacial lakes}

PDMS samplers at the sites P2-P4, located in the lower lake and the stream between the two lakes, revealed
Fig. 5 iPCB (red dotted line) and ${ }^{137} \mathrm{Cs}$ (striped bars) concentrations in the sediment from the Silvretta lake, averaged over 10 -cm sections

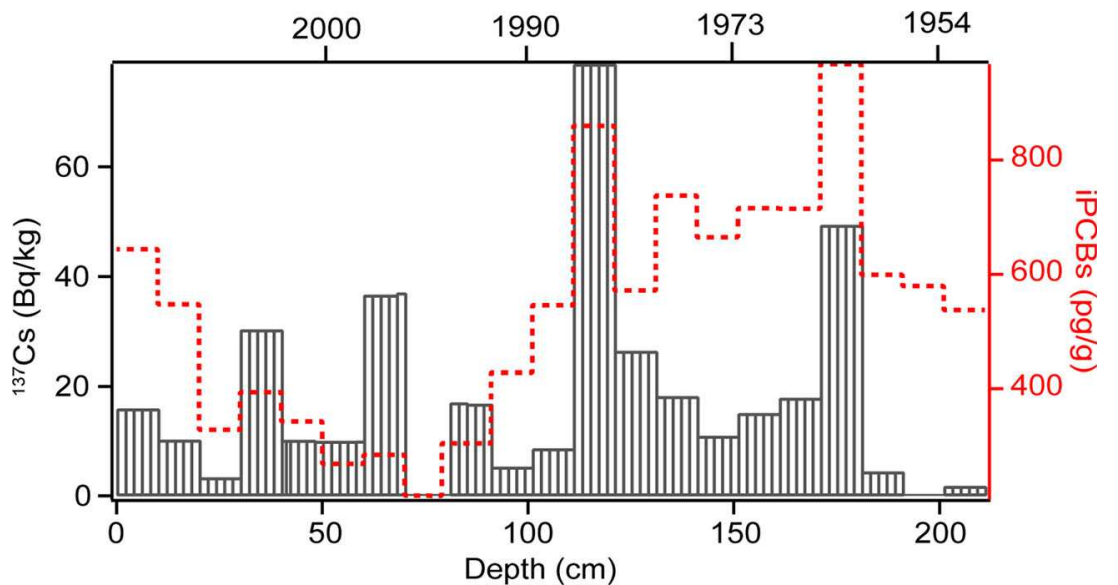



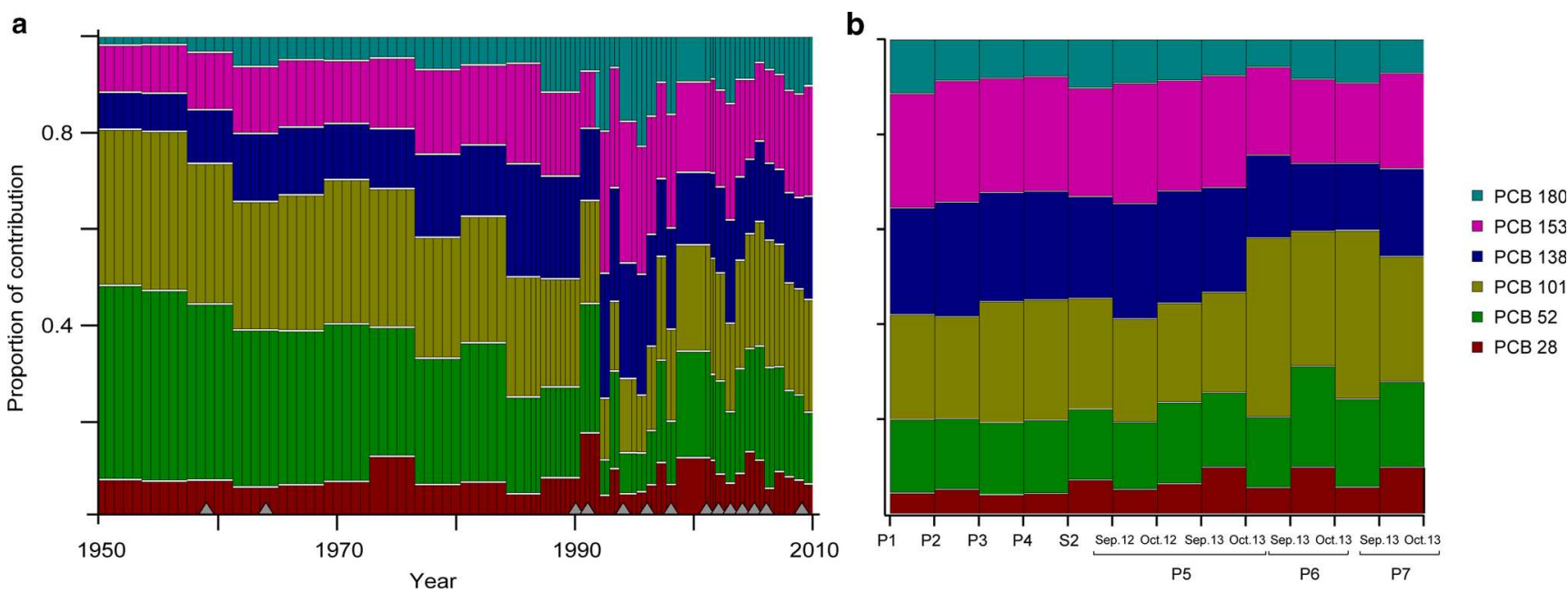

Fig. 6 PCB congener pattern. (a) in the sediment from the Silvretta lake. The grey triangles show years with negative glacier mass balance (Huss et al. 2008). (b) in the PDMS samples

concentrations of iPCBs of $330-530 \mathrm{pg} / \mathrm{g}$ PDMS. The concentration in the surface-sediment sample from $\mathrm{S} 2$ is $743 \mathrm{pg} / \mathrm{g}$ and thus slightly higher. The sampling site P1 (in the upper lake S1) is characterised by the lowest concentrations of $78 \mathrm{pg} / \mathrm{g}$ PDMS, in accordance with the assumption that the main input of pollutants to this lake currently is from the atmosphere and not glacier meltwater. The overall congener patterns of sediments (Fig. 6) and PDMS samplers (Fig. 4) are very similar. The pronounced dominance of the congeners with 4 to 7 chlorine atoms (PCB 101, PCB 138, PCB 153, and PCB 180) is explained with the hydrophobicity and the sorption affinity of these congeners.

The loads of the PDMS samplers in the catchment area at the different sites and the different sampling periods are relatively uniform with iPCB values ranging between 300 and $450 \mathrm{pg} / \mathrm{g}$ PDMS (Fig. 4). There is no concentration gradient with increasing distance from the glacier terminus. In general, the iPCBs concentrations in October are slightly lower than those in September, and in 2012 lower than 2013, probably because of the lower temperatures, respectively, less melting and higher precipitation rates (data from meteoswiss.ch). The sampling site P6 is in the non-glacier-fed stream and is characterised with similar loads as the glacier-fed one. Bizzotto et al. (2009) reported comparable results, showing that the PCB concentrations do not decrease with decreasing distance from the glacier terminus and that there is no significant variance of the PCBs loads between glacier-fed and nonglacier-fed streams.

In addition, the calculated water concentrations based on the PDMS data also show a relatively uniform pollutant load, which is a factor of 2-5 lower than the measured bulk water samples (Table 1). As water samples were not filtered before extraction, the measured PCB concentrations represent both the adsorbed and the soluble fractions. In contrast, passive samplers represent only the soluble fraction. Thus, higher loads in the bulk samples correspond to higher concentration of particle-bound PCBs. Both calculated and measured water concentrations are in the lower end of the range reported for Switzerland (20-600 ng/L) (Schmid et al. 2010). suggesting that the influence of remobilisation of iPCBs from the glacier reservoir is of minor importance in the catchment of the Silvretta glacier, in contrast to the proglacial lake sediment. This might be due to the dilution of the signal between the glacier terminus and the downstream sites or the fact that the ice containing the highest loads of iPCBs has already been melted.

\section{Conclusions}

We quantified the release of PCBs from a glacier by measuring iPCB concentrations in different compartments of the Silvretta glacier catchment area. According to our data from a proglacial lake sediment core, PCBs have been released during the last 10 years at rates similar to the time of their production. This observation is explained with the extensive melting of the Silvretta glacier starting in the 1990s. In contrast, the pollutant loads in the other compartments of the glacier catchment are currently relatively homogeneous, indicating that, in the case of the Silvretta glacier, the influence of PCBs release due to accelerated glacier melt is confined to the proglacial lake.

Acknowledgments The authors are thankful to Marian Funk (Eawag Dübendorf) for the ${ }^{137} \mathrm{Cs}$ analysis. The Swiss National Science Foundation is acknowledged for the financial support (Grant Nr 200021_130083/ 1 and 200020_149835/1) 


\section{References}

Anselmetti FS, Bühler R, Finger D, Girardclos S, Lancini A, Rellstab C, Sturm M (2007) Effects of Alpine hydropower dams on particle transport and lacustrine sedimentation. Aquat Sci 69:179-198

Appleby PG, Birks HH, Flower RJ, Rose N, Peglar SM, Ramdani M, Fathi AA (2001) Radiometrically determined dates and sedimentation rates for recent sediments in nine North African wetland lakes (the CASSARINA Project). 347-367

Bettinetti R, Quadroni S, Galassi S, Bacchetta R, Bonardi L, Vailati G (2008) Is meltwater from Alpine glaciers a secondary DDT source for lakes? Chemosphere 73:1027-1031

Bettinetti R, Galassi S, Guilizzoni P, Quadroni S (2011) Sediment analysis to support the recent glacial origin of DDT pollution in Lake Iseo (Northern Italy). Chemosphere 85:163-169

Bizzotto EC, Villa S, Vaj C, Vighi M (2009) Comparison of glacial and non-glacial-fed streams to evaluate the loading of persistent organic pollutants through seasonal snow/ice melt. Chemosphere 74:924-930

Blais JM, Schindler DW, Muir DCG, Sharp M, Donald D, Lafrenière M, Braekevelt E, Strachan WMJ (2001) Melting glaciers: a major source of persistent organochlorines to subalpine Bow Lake in Banff National Park. Canada Ambio 30:410-415

Bogdal C, Schmid P, Kohler M, Müller CE, Iozza S, Bucheli TD, Scheringer M, Hungerbühler K (2008) Sediment record and atmospheric deposition of brominated flame retardants and organochlorine compounds in Lake Thun, Switzerland: lessons from the past and evaluation of the present. Environ Sci Technol 42:6817-6822

Bogdal C, Schmid P, Zennegg M, Anselmetti FS, Scheringer M, Hungerbühler K (2009) Blast from the past: melting glaciers as a relevant source for persistent organic pollutants. Environ Sci Technol 43:8173-8177

Breivik K, Sweetman A, Pacyna JM, Jones KC (2007) Towards a global historical emission inventory for selected PCB congeners-A mass balance approach-3. An update. Sci Total Environ 377:296-307

Elbert J, Grosjean M, von Gunten L, Urrutia R, Fischer D, Wartenburger R, Ariztegui D, Fujak M, Hamann Y (2011) Quantitative highresolution winter (JJA) precipitation reconstruction from varved sediments of Lago Plomo 47 S, Patagonian Andes, AD 1530 2002. The Holocene 22:465-474

Huss M, Bauder A (2009) 20Th-century climate change inferred from four long-term point observations of seasonal mass balance. Ann Glaciol 50:207-214

Huss M, Bauder A, Funk M, Hock R (2008) Determination of the seasonal mass balance of four Alpine glaciers since 1865. J Geophys Res 113:F01015

Leemann A, Niessen F (1994) Holocene glacial activity and climatic variations in the Swiss Alps: reconstructing a continuous record from proglacial lake sediments. The Holocene 4:259-268
Moschet C, Vermeirssen ELM, Seiz R, Pfefferli H, Hollender J (2014) Picogram per liter detections of pyrethroids and organophosphates in surface waters using passive sampling. Water Res 66C:411-422

Nellier YM, Perga ME, Cottin N, Fanget P, Naffrechoux E (2015) Particle-dissolved phase partition of polychlorinated biphenyls in high altitude alpine lakes. Environ Sci Technol. doi:10.1021/acs. est. 5 b01274

Pavlova PA, Schmid P, Zennegg M, Bogdal C, Schwikowski M (2014) Trace analysis of hydrophobic micropollutants in aqueous samples using capillary traps. Chemosphere 106:51-56

Röllin S, Beer J, Balsiger B, Brennwald M, Estier S, Klemt E (2013) Radionuklide in Sedimenten des Bielersees. 1-6

Rusina TP, Smedes F, Koblizkova M, Klanova J (2010) Calibration of silicone rubber passive samplers: experimental and modeled relations between sampling rate and compound properties. Environ Sci Technol 44:362-367

Schmid P, Zennegg M, Holm P, Pietsch C, Brüschweiler B, Kuchen A, Staub E, Tremp J (2010) Polychlorierte Biphenyle (PCB) in Gewässern der Schweiz. Daten zur Belastung von Fischen und Gewässern mit PCB und Dioxinen, Situationsbeurteilung. Umwelt-Wissen Nr. 1002. www.bafu.admin.ch/publikationen/ publication01518

Schmid P, Bogdal C, Blüthgen N, Anselmetti FS, Zwyssig A, Hungerbühler K (2011) The missing piece: sediment records in remote mountain lakes confirm glaciers being secondary sources of persistent organic pollutants. Environ Sci Technol 45:203-208

Steinlin C, Bogdal C, Scheringer M, Pavlova PA, Schwikowski M, Schmid P, Hungerbühler K (2014) Polychlorinated biphenyls in glaciers. 2. Model results of deposition and incorporation processes. Environ Sci Technol 48:7849-7857

Thevenon F, de Alencastro LF, Loizeau J-L, Adatte T, Grandjean D, Wildi W, Poté J (2013) A high-resolution historical sediment record of nutrients, trace elements and organochlorines (DDT and PCB) deposition in a drinking water reservoir (Lake Brêt, Switzerland) points at local and regional pollutant sources. Chemosphere 90: 2444-2452

UNEP: Stockholm Convention on Persistent Organic Pollutants (2004) United Nations Environment Programme. www.chm.pops.int

Vermeirssen ELM, Dietschweiler C, Escher BI, Van der Voet J, Hollender J (2012) Transfer kinetics of polar organic compounds over polyethersulfone membranes in the passive samplers pocis and chemcatcher. Environ Sci Technol 46: 6759-6766

Vilanova R, Fernández P, Martínez C, Grimalt JO (2001) Organochlorine pollutants in remote mountain lake waters. J Environ Qual 30:1286-1295

Wania F, Westgate JN (2008) On the mechanism of mountain coldtrapping of organic chemicals. Environ Sci Technol 42:9092-9098 